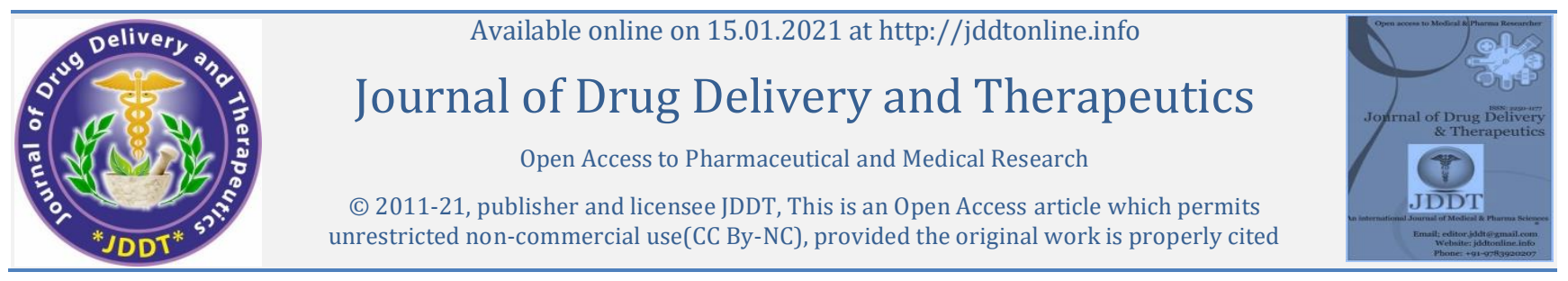

Open Access Full Text Article

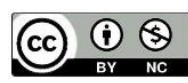

Letter to Editor

\title{
Global Epidemiology of COVID-19 and the Risk of Second Wave
}

\author{
Arslan Habib ${ }^{1}$ iD , Khalid Mahmood Anjum ${ }^{1}$, Zeeshan Ashraf ${ }^{2}$, Umutumwa Eric Principe ${ }^{2}$, Zahid Hussain ${ }^{3}$, Bilal Khalid ${ }^{3}$ \\ and Muhammad Ramzan ${ }^{4}$,
}

${ }^{1}$ Lab of Molecular Immunology, School of Life Sciences, Fudan University, Shanghai, China

${ }^{1}$ Department of Wildlife \& Ecology, University of Veterinary and Animals Sciences, Lahore, Pakistan

${ }_{2}^{2}$ Department of Fisheries \& Aquaculture, University of Veterinary and Animals Sciences, Lahore, Pakistan

${ }^{2}$ School of Biotechnology, East China University of Science \& Technology, Shanghai, China

${ }^{3}$ Department of Zoology, Division of Science \& Technology, University of Education, Lahore, Pakistan

3,4 Department of Zoology, University of the Punjab, Lahore, Pakistan

Article History: Received 22 Nov 2020; $\quad$ Review Completed 18 Dec 2020 Accepted 21 Dec 2020; Available online 15 Jan 2021

*Address for Correspondence: Arslan Habib, Lab of Molecular Immunology, School of Life Sciences, Fudan University, Shanghai, China ORCID ID: https://orcid.org/0000-0001-5771-6411

Cite this article as: Habib A, Anjum KM, Ashraf Z, Principe UE, Hussain Z, Khalid B, Ramzan M, Global Epidemiology of CoVID-19 and the Risk of Second Wave, Journal of Drug Delivery and Therapeutics. 2021; 11(1):1-2 DOI: http://dx.doi.org/10.22270/jddt.v11i1.4653

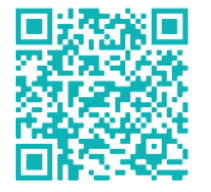

Dear Editor; Globally all over the countries the risk of respiratory disease with the name of novel coronavirus disease 2019 (ncovid-19) is the major health issue. Coronaviruses are the important pathogens of human and animals. A novel coronavirus was first time observed at the end of 2019 in Wuhan city of China which affects the respiratory system of humans. The epidemic of virus spread quickly all over the China which increased the number of active cases then it moved to other countries globally. World Health Organization (WHO) named the disease as coronavirus disease 2019 (Covid-19) at the end of February 20201 . The deadly virus responsible for the corona virus disease 2019 named as severe acute respiratory syndrome coronavirus 2 (SARS-CoV-2) but before this that was known as 2019-nCoV. According to genome analysis and the evolutionary expression the coronavirus that is responsible for covid-19 is a betacoronavirus with subgenus similar to severe acute respiratory syndrome (SARS) and bat coronavirus but in different order 2. The International Committee on Taxonomy of Viruses about the coronavirus research class nominated this virus as severe acute respiratory syndrome coronavirus 2 (SARS-CoV-2) ${ }^{3}$. Covid19 is sometimes asymptomatic but the obvious symptoms are pyrexia, cold, flu, dry cough shortness of breath, respiratory dysfunction, vomiting, diarrhea, arthralgia, body aches and inability to arouse 4 . The present study was designed to measure the epidemiology of Covid-19 all over the world. The data about covid-19 cases were collected from official website of government of Pakistan and the John Hopkins university daily covid-19 updates website. To measure the epidemiology of covid-19 all over the world QGIS 3.16 geographic information software was used and analyzed the active cases of $25^{\text {th }}$ November 2020. The government of Pakistan website covid-19 data was used for the graphical representation of the cases as shown in the figure 2. A total of 26 countries were selected to measure the prevalence of active cases. It was observed that United State of America (USA) was much more affected with 12956783 active cases, 265956 deaths and 7639084 recoveries as compared to other countries followed by India with 9222216 active cases, 134743 deaths and 8642771 recoveries, Brazil with 6121449 active cases, 170179 deaths and 5476018 recoveries then Russia with 2162503 active cases, 37538 deaths and 1660419 recoveries 5 . The prevalence of covid-19 in all the other countries can be observed from the covid-19 epidemiological graph as shown in the figure 2 . The statistics are kept changing on daily basis with updates of cases on the online database websites.

Globally all the countries are under the threat of second wave of covid-19 but there is no exact definition of second wave of covid-19. In many countries the second wave reappears in different shapes. Association of schools of public health in the European region (ASPHER) defined the term second wave as reappearance of the active cases in the current pandemic, which increases the number of patients at exponential rate in a specific time and the given territorial sector. This exponential rate follows from the disappearance or close to disappearance of patients of the disorder and can be encouraged with the aid of using a new behavioral function of the infectious agent or a changed function from some other already known ${ }^{6}$. All over the globe Nonpharmaceutical steps have that were applied during the first wave are the major response to fight against the disease which includes test and trace facility, keep social distancing, face mask facility, isolation \& quarantine centers, personal protective equipment and avoidance of huge gathering in public places 7 .

In order to minimize the risk of covid-19 transmission different strategies should be adopted by everybody which include avoid from public gatherings, always use face mask, hand sanitization, closure of public parks, stay at home, screening should be compulsory at entry \& exist points, reduce the travelling, isolation should possible in case of infection. 


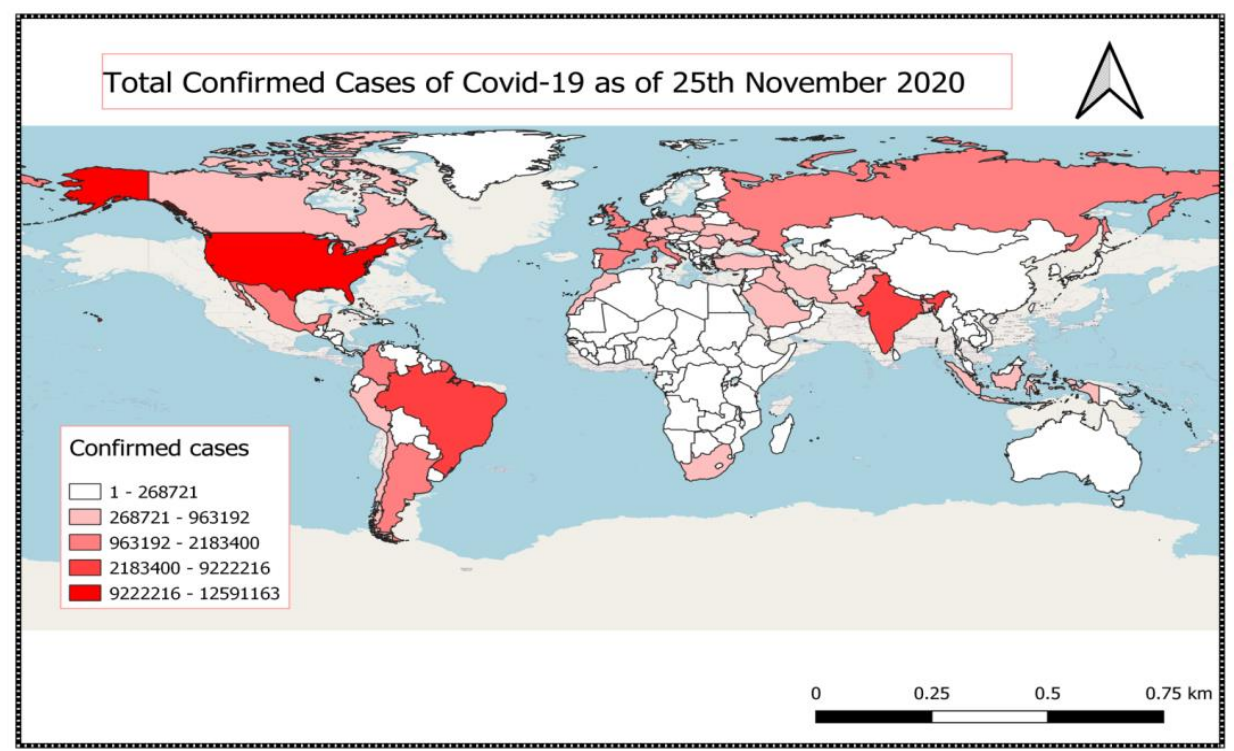

Figure 1: Spatial distribution map of Covid-19 epidemiology

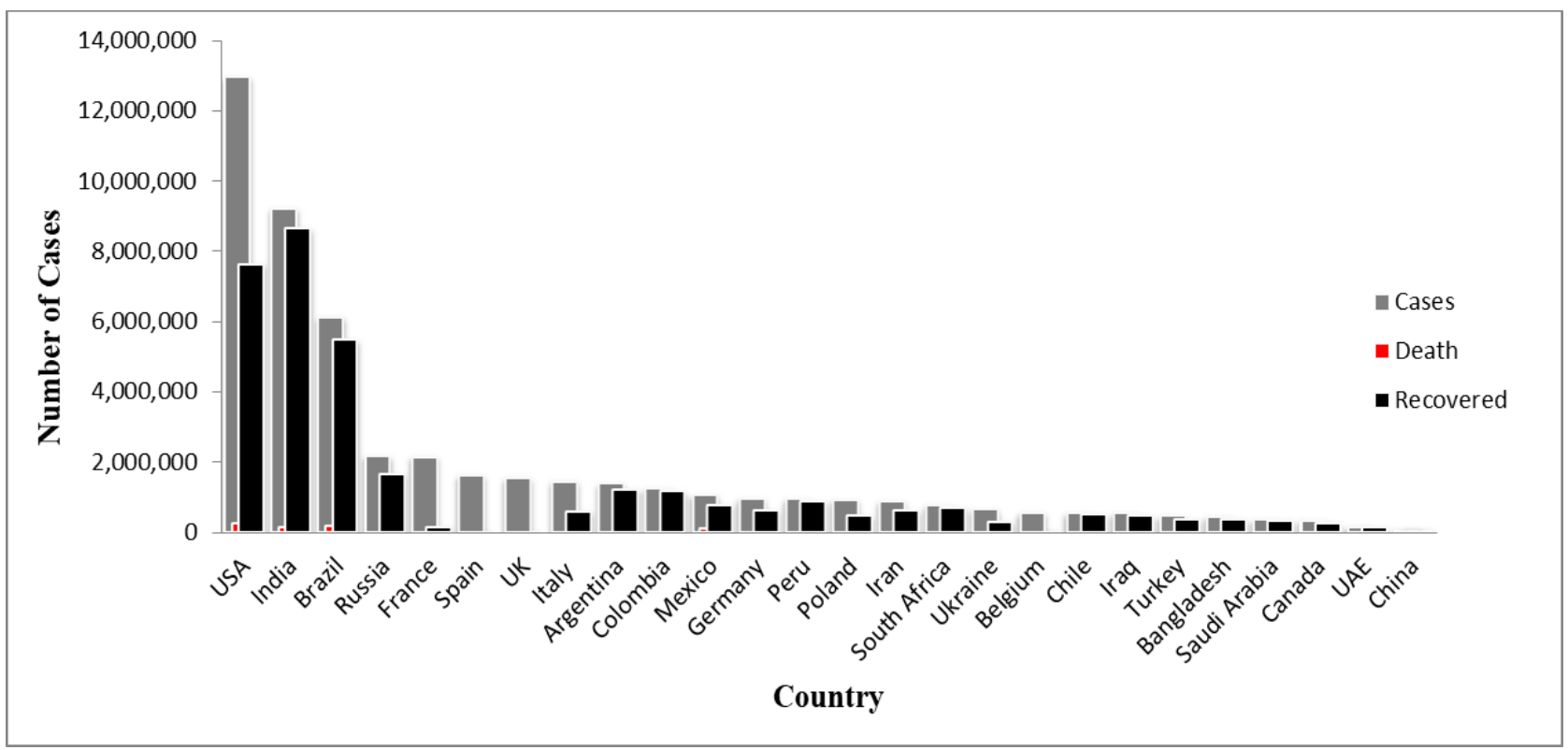

Figure 2: Country-wise Covid-19 epidemiological graph

In conclusion Covid-19 is a global health problem which requires a global effort to eliminate the risk of virus transmission. Now all the countries are at the risk of second wave. It's very necessary for every individual to follow the preventive rules \& regulations recommended by World Health Organization.

\section{Authors Contribution:}

All the authors contribute equally in the collection of data and to help in the mapping of global Covid-19 prevalence map. All the authors support technically and responsible for manuscript reviewing, data analysis.

\section{Conflict of Interest:}

All the authors declare no conflict of interest

\section{References}

(1) McIntosh, K., Hirsch, M., Bloom, A. Coronavirus disease 2019 (COVID-19): Epidemiology virology and prevention. The Lancet Infectious Diseases, 2020; (1):2019-2020.

(2) Zhou, P., Yang, X-L., Wang, X-G., et al. A pneumonia outbreak associated with a new coronavirus of probable bat origin. Nature, 2020; 579(7798):270-273.

(3) Gorbalenya, AE., Baker, SC., Baric, R., et al. Severe acute respiratory syndrome related coronavirus: The species and its viruses a statement of the Coronavirus Study Group. 2020.

(4) Mudenda, S. Letter to Editor: Coronavirus Disease (COVID-19): A Global Health Problem. International Journal of Pharmaceutics \& Pharmacology, 2020; 4(1).

(5) Coronavirus in Pakistan. Government of Pakistan: COVID-19 Health Advisory Platform, Ministry of National Health Services. Available from: http://covid.gov.pk. (assessed 25 November 2020).

(6) Yiangou, A., Makin, S., Cope, C., Laycock, E. Preparing for a challenging winter 2020/21. 2020.

(7) Middleton, J., Lopes, H., Michelson, K., \& Reid, J. Planning for a second wave pandemic of COVID-19 and planning for winter. International Journal of Public Health, 2020; (65): 1525-1527. 